\title{
Electrical Safety Audit in a Healthcare Unit
}

\section{Ramesh, M. Madhusudhana Raju, Vijayakumar Mani}

\begin{abstract}
All things considered, it is critical to pursue the equivalent deliberate methodology utilized for other wellbeing and security issues, when managing electrical wellbeing. Electrical Safety Audit is a deliberate method to manage evaluate potential risks and to recommend recommendations for advancement. ESA in Health care unit is a crucial gadget for perceiving of standards, regions of threats or shortcoming, dangers and potential disasters in an Office, Facility or Plant for choosing fundamental movement to/limit risks and for ensuring that the whole security effort is suitable and huge. Electrical Safety Audit carried out for Hospitals at their site premises and Objectives of Electrical Safety Audit is carry out in accordance with "Audit \& Verification of Compliance" of the facility to general electrical safety, as per Indian Regulations - Indian Electricity Rules IER, IS 2309, IS 3043 etc. Highlight the areas of concern, with recommendations for actions and improvisation measures and also to identify the adequacy of existing procedures and training needs with respect to electrical safety.
\end{abstract}

Keyword: Electrical Safety Audit, Electrical Safety Standards, Electrical Hazards, Recent Development in Power Quality Study.

\section{INTRODUCTION}

\section{Methodology of Electrical Safety Audit}
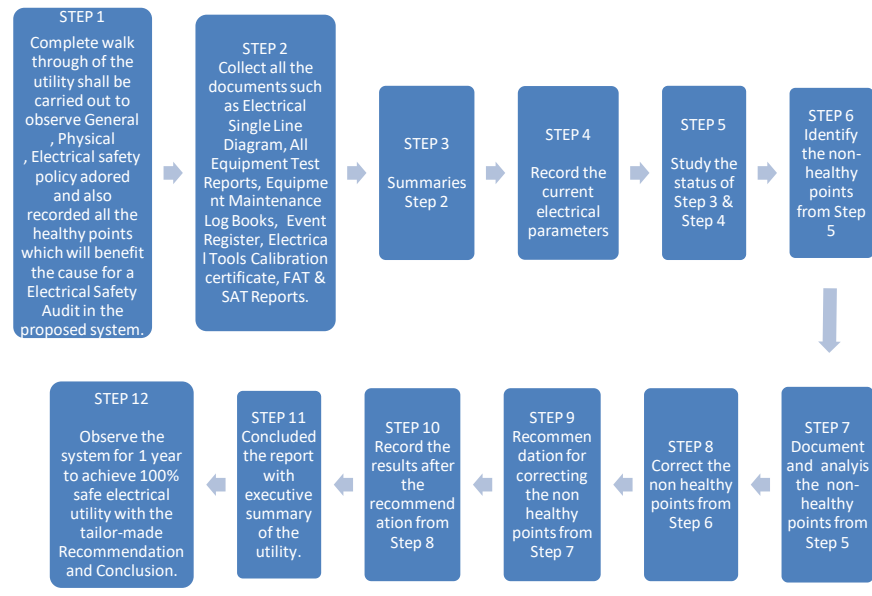

The methodology and checklists have been finalized and implemented jointly in discussions with the facility occupier. The checklist has been prepared incorporating the local regulations, National/International codes. Energy Consumption guidelines and internal requirements \& expectations of the facility occupier. The checklists have

Revised Manuscript Received on November 27, 2019.

* Correspondence Author

Dr. L. Ramesh, Professor Dr.M.G.R Educational \& Research Institute University, Chennai

Er.M. Madhusudhana Raju , Electrical - Testing Engineer, Applus Velosi, Muscat - Oman.

Er. Vijayakumar Mani, Head Electrical- Applus Velosi, Muscat Oman. been customized to suit the location under discussions with the respective facility occupiers

Electrical Safety: Over $40 \%$ fire accidents happen due to fault in electric circuits, connections and always electrical system is a threat to safety of people and their property in the form of shocks, burns, injury, fire and explosion which cause damage to expensive communication equipment, loss of data, fire incable gallery, etc.

\section{Electrical Safety Audits helps in identifying:}

Electrical hazards to minimize the risk of accidents like fire due to short-circuiting, Areas of risk or vulnerability in electrical systems and installations, Non-compliance with the legislation and best practices.

\section{II.REVIEW}

As per [1] In any industrial, commercial, and residential area the three top operating expenses are found to be energy, material or machine and labor. On the energy demand and supply side, India is facing severe shortage. $70 \%$ of the total petroleum product demand is being met by imports, imposing a heavy burden on foreign exchange. Country is also facing peak power and average electricity shortage of $12 \%$ and $7 \%$ respectively. An energy study of various sector of commercial industrial and residential area indicates that 5-20\% energy can be saved.

As per [2] A construction site is one of the most risky, perilous and accident-prone working environments. The safety audit management system is one step to achieve a better, safe and accident-free working environment. A safety audit was prepared on MS Excel and 19 major elements were selected for the study. The audit was implemented in SSH International, Kuwait. For the collection of data for the audit, physical checks/inspections were done. Safety records, safety logs, safety registers, minutes of safety meetings, etc. were assessed. The factors that could affect the health and safety of the workers at the site were then ranked based on their criticality. The audit score for the consultancy was $79 \%$. Out of the 19 audits elements, 6 elements were ranked as the primary and secondary causes of accidents. The improper usage of the following 6 elements could affect the Health and the safety of the construction personnel at the aforementioned construction site. The six elements were the following: Amenities/Sanitation, Electrical Works, Excavations, Tools and equipment, Fire protection and hot works, and Personal Protective Equipment's (PPE's). The practical implication of the audit is that the actual work-site conditions could be taken into account through the audit, and based on the happenings at the work-site, suggestive measures could be given.

As per [3] Occupational risk management is known as a catalyst in generating superior returns for 
all stakeholders on a sustainable basis. A number of companies in Ghana implemented health and safety measures adopted from international companies to ensure the safety of their employees. However, there exist great threats to employees' safety in these companies. The purpose of this paper is to investigate the level of compliance of Occupational Health and Safety management systems and standards set by international and local legislation in power producing companies in Ghana.

\section{AUDITED HEALTH CARE UNIT}

The Healthcare Unit located in Chennai with nearly 1500 personals are working in the Hospital. The electricity needs of this office are mainly meet by the supply from two Main Substation in the hot of the city provided by the TNEB, it is supplement by 5 diesel generator unit during emergencies/total supply failure. This building prominence in the network as a redundancy and it became essential to ensure the electrical safety of the building. The personal and the equipment's housed in it at its best, the equipment and health safety risks is measured by conducting safety audit to identify

the

condition.

- To assess the vulnerability of Hospitals/Health facilities from non-structural elements.

- To assess the preparedness of hospitals/health facilities to prevent or minimize the loss of lives during emergencies and disasters in respective towns/districts.

- To recommend non-structural mitigation measures for each hospital/health facilities to respond to the need of communities especially during emergencies. The safety audit mainly focuses on the threats faced by the building and electrical installation and personal safety hazard and based on the availed data we have conducted the safety audit.

The issue that come under it focus are $>$ The safety of the building and equipment housed in it from harmful effects of lighting and other over voltage surges and polluted external power supply (harmonics).

$>$ The personal safety hazard-the safety of the operating personal, Communication server and executives working in this building

$>$ The operating status of the electrical equipment and devices employed in the building and the maintenance performed, the adequacy of the protection afforded to them and also the condition of the protective earth connection and electronics

$>$ Compliance of I.E Rules and the use of electrical equipment and devices with bus mark. among the main equipment/devises that were subjected to the "Safety scanner" are

$>$ Diesel generating unit

$>$ Power factor correcting capacitors.

$>$ Air conditioning Unit

$>$ Elevators and storage batteries

$>$ Electric equipment housed inside the building

\section{AVAILED DATA'S}

Working Area: 25000 Sq. (Approx.)

Working Personnel's: 1500 No's

Sanctioned Demand: 1200 KVA

Source: EB / DG
On synthesizing the inspections/studies performed at various locations and levels of the building the following general views are arrived as:

- The Lighting protection of the building is available.

- Maintenance of the electrical equipment in the Electrical Power Room is being done on Annual contract basis.

- The maintenance thus carried out have not been recorded in the equipment history cards/maintenance registers. No approved emergency/routine operating instructions are available for the guidance of the operating personnel.

- $\quad$ Record has been made on the hourly readings of the meters provided for the equipment in the Power and at various levels.

\section{a. Major Concerned Areas, where immediate Response is required.}

- Firefighting equipment is provided at all floors and some firefighting equipment is not been tested.

- Concealed wiring system has been adopted for the distribution of electric power in the building. It is functions well, but at certain points, it is kept uncovered.

- The Rusted earth connection to the vital Panels may be replaced with copper

- Conductors of adequate size.

- Earthing Efficacy is adequate.

- Lightening System is inadequate.

- Load Balancing should be achieved by means of load planning.

- Unwanted materials are stagnated inside the Hospital Premises.

\section{b. Safety Insulation Mats}

Safety insulation mats as per IS: 15652 superseding IS:5424/69 was introduced in the year 2007, with the view of technical advancement \& more safeguard life of electricians\& other technicians, in case of any accidental current leakage while working on AC or DC installations. Synthetic insulation mat confirms complete safety of workers handling live electronic equipment's.

Continuous abrasion of electrical rubber mats due to regular foot movement over it, results in distortion of physical, mechanical \& electrical properties of mat. Therefore, regular inspection is recommended for confirmation of appropriate working of mats. Any sign of deformation mean replacement of part or entire mat.

\section{c. Electrical Safety Insulating Gloves \& Insulating Boots}

There are 2 main types of insulating gloves

1. Latex Gloves - provides high dielectric performance and must be used with leather over gloves for mechanical protection.

2. Composite Gloves - provide superior mechanical protection against punctures and tears eliminating the need for over gloves.

3. Wearing suitable PPE to protect electrical engineers, cable jointers and linesmen against dangers posed by exposure to electric cables and circuits is essential. Insulating gloves must be flexible and durable 
with high dielectric strength complaint with IEC 60903. Summary of the observation for Lighting Protection Summary of the observation for lighting Protection

\begin{tabular}{|c|l|c|l|}
\hline S.No & \multicolumn{1}{|c|}{ Description } & Ref. Std & \multicolumn{1}{|c|}{ Status/Recommendation } \\
\hline 01 & $\begin{array}{l}\text { Is the installations as per the approved } \\
\text { design? }\end{array}$ & IS 3043 & Design document is not available \\
\hline 02 & $\begin{array}{l}\text { Are identification marks present and } \\
\text { in line with drawings? }\end{array}$ & IS 3043 & $\begin{array}{l}\text { Most of the pits are found without } \\
\text { identification marks and has to be } \\
\text { updated as per layout. }\end{array}$ \\
\hline 03 & Is the earth pit maintenance effective? & IS 3043 & $\begin{array}{l}\text { Care should be taken for improving } \\
\text { the condition of individual pit } \\
\text { resistance values like treating the soil, } \\
\text { pouring water and monitoring the } \\
\text { resistance values at regular interval } \\
\text { period (twice in a year). }\end{array}$ \\
\hline 04 & $\begin{array}{l}\text { Are earth resistance measured } \\
\text { periodically? }\end{array}$ & IS 3043 & Records not available. \\
\hline 05 & Is the earth continuity tested? & IS 3043 & $\begin{array}{l}\text { Couldn't be identified since it is } \\
\text { buried under the ground. }\end{array}$ \\
\hline
\end{tabular}

\begin{tabular}{|c|c|c|c|}
\hline S.No & Deschiption & Observation & Status/Recommendation \\
\hline 1. & $\begin{array}{l}\text { Type of constuction (Roof, walls, } \\
\text { metal ,chimmey-continuity issues) }\end{array}$ & Walls & Nol \\
\hline 2. & Extemal Lightming Protection & Practically Available & Nil \\
\hline 3. & Physical condition of air circulation & Good & Meeting the requirement \\
\hline 4. & $\begin{array}{l}\text { Condition and number of earth } \\
\text { connections }\end{array}$ & $\mathrm{NA}$ & Nil \\
\hline 5. & Presence of test link & Good & Meeting the requirement \\
\hline 6. & $\begin{array}{l}\text { Height of the air terminal from the } \\
\text { ground }\end{array}$ & $\mathrm{NA}$ & Meeting the requirement. \\
\hline 7. & $\begin{array}{l}\text { Present lighhing protection } \\
\text { maintenance details }\end{array}$ & NA & Not Meeting the regurement \\
\hline 8. & Details of lighming/Surge accidents & NA & Nil \\
\hline 9. & Earth Pits & Good & Meeting the requirement. \\
\hline 10. & Protection Zone & $\mathrm{NA}$ & Nal \\
\hline
\end{tabular}

\section{OBSERVATION OF ELECTRICAL UTILITIES}

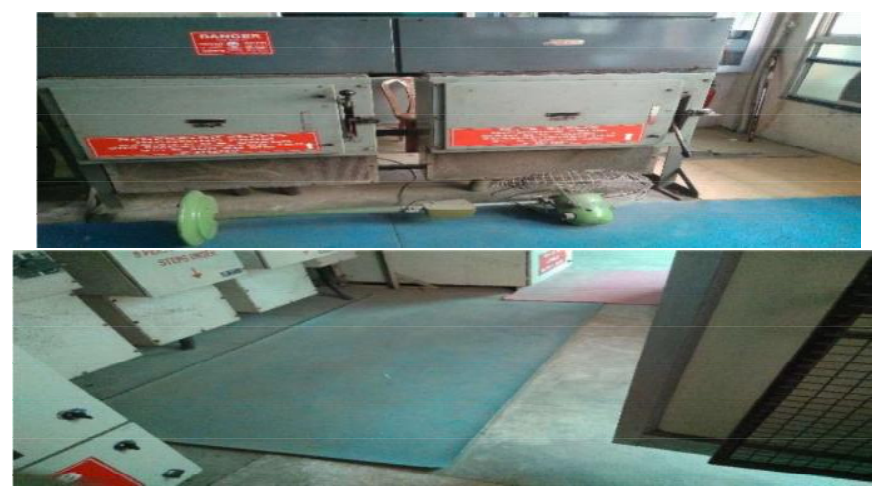

Case 1: Observation: Heating of terminals are identified. Old switchgear is present with very less ground clearance. Fans are used to cool the breaker terminals. Recommendation: Switchgears should be replaced with new one with proper ground clearance. Case 2: Observation: Rubber mat are not as per standard. Recommendation: Proper Rubber mat should be provided as per IS 15652 .

Case-1

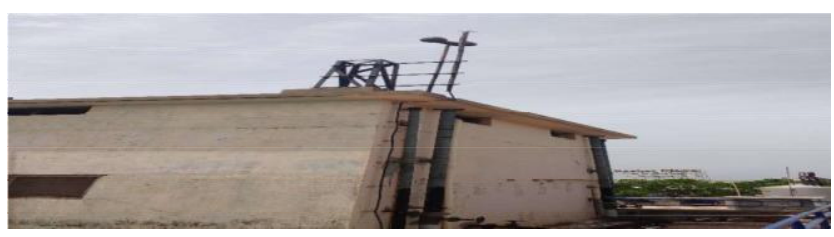

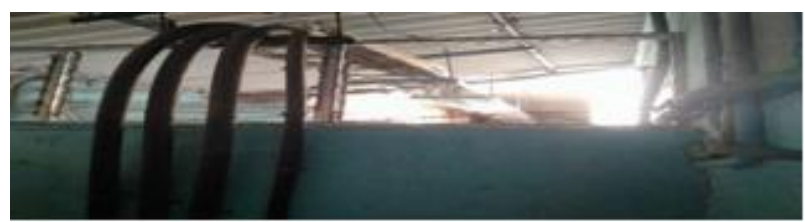

Case-2

Case 1: Observations: Fixed Angle Air Termination two spike rod was found. Recommendations: It is in good condition, but it will cover very limited area. Additional Lightening system gives more safety to the premises. Case 2: Observation: Cable trays are not present Recommendation: Cables should be lay in cable trays.

Case-1
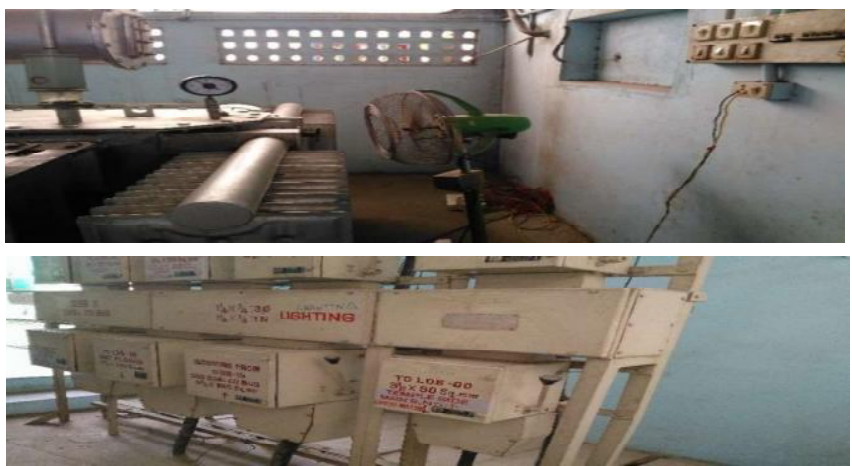

Case-2

Case 1: Observation: Transformer Temporary cooling fans are available. Recommendation: Replace the temporary fans to permanent cooling system of transformer Case 2: Observation: Proper Name plate \& addressing of the MCCB is done. Recommendation: Proper Name plate $\&$ addressing of the MCCB is done.

Case-1
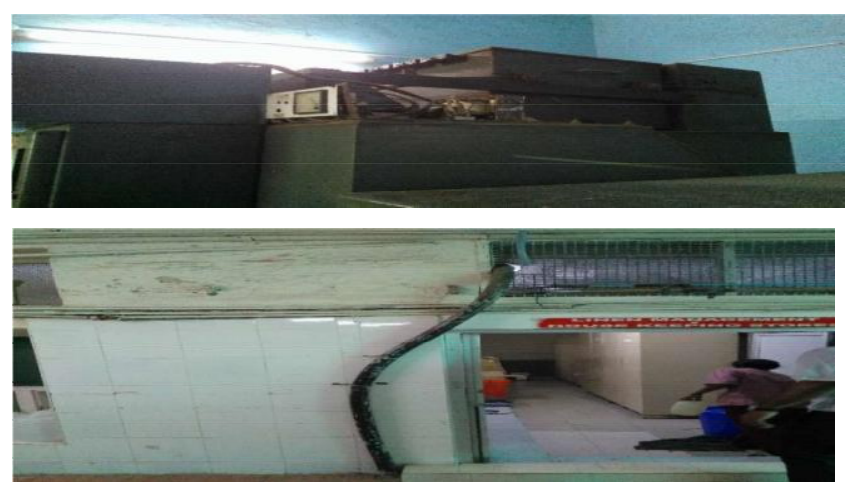

Case-2

Case 1: Observation: Auxiliary transformer for mechanical box is opened and no protection is carried out. Recommendation: Auxiliary transformer for mechanical box should be properly closed. Case 2: Observation: In proper Cable Entry. Recommendation: Cable Entry should be done at underground only. 

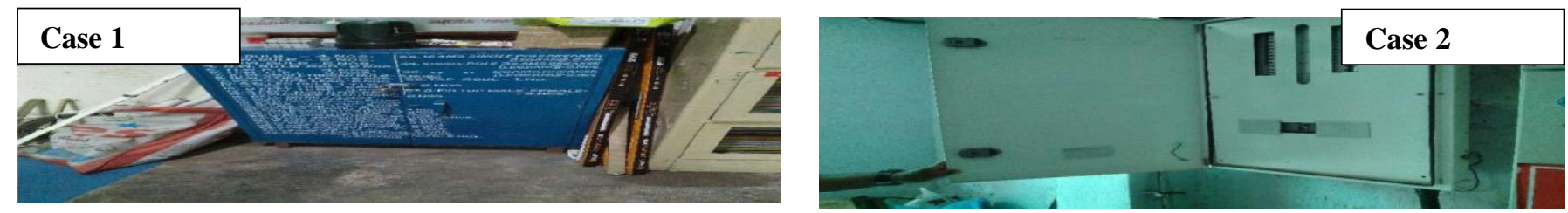

Case 1: Good Practice of naming the tools \& tackles Case 2: Observation: Panel earthing is not available. Recommendation: Panel earthing should be done.
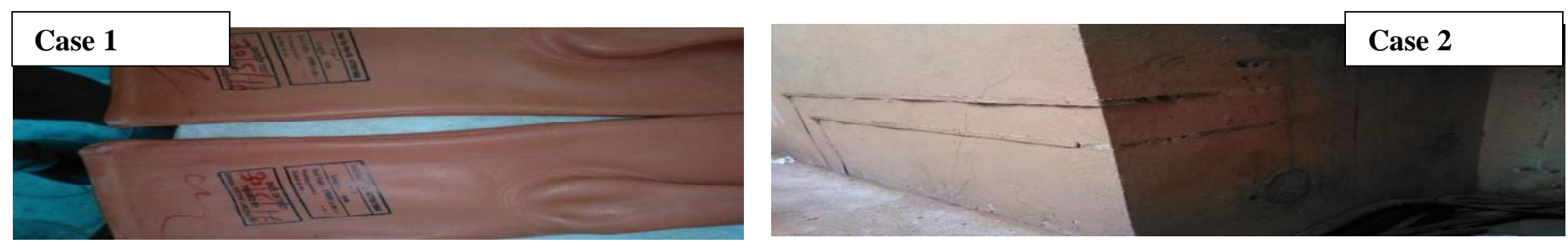

Case 1: Observation: Rubber glouse testing expired. Recommendation: As IEC60903, rubber glouse should be tested for every 6 months. Case 2: Observation: Copper Flat track is missing. Recommendation: Copper Flat shall be layed to achieve proper grounding.
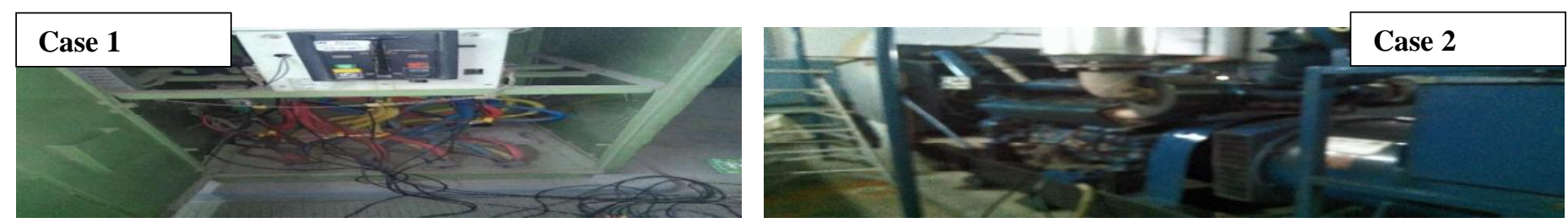

Case 1: Observation: Generator power quality testing carried out. Supporting results in Power Quality Study. Recommendation: Results attached in PQA study. Case 2: Observation: Proper Earth mat is missing. Recommendation: Earth mat should be provided.
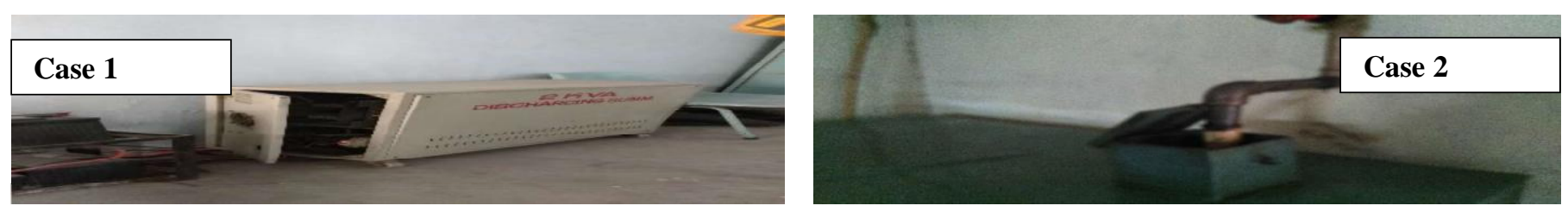

Case 1: Observation: UPS Control panel is opened while in running condition.Recommendation: Battery should be enclosed and rubber mate should be provided. UPS Control panel is opened while in running condition, should be properly closed. Case 2: Observation: Diesel entry in the diesel Day Tank can't be closed. Recommendation: Necessary arrangement should be provided to close the diesel entry.
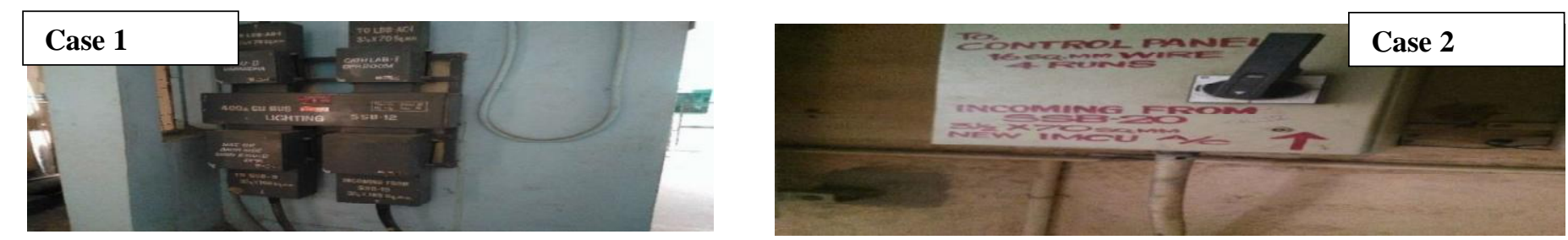

Case 1: Observation: Proper Name plate \& addressing of the panel is missing. Recommendation: It should be provided with Electrical Name plate Stickering. Case 2: Observation: Gland Earthing is not present. Recommendation: Gland earthing should be provided. 

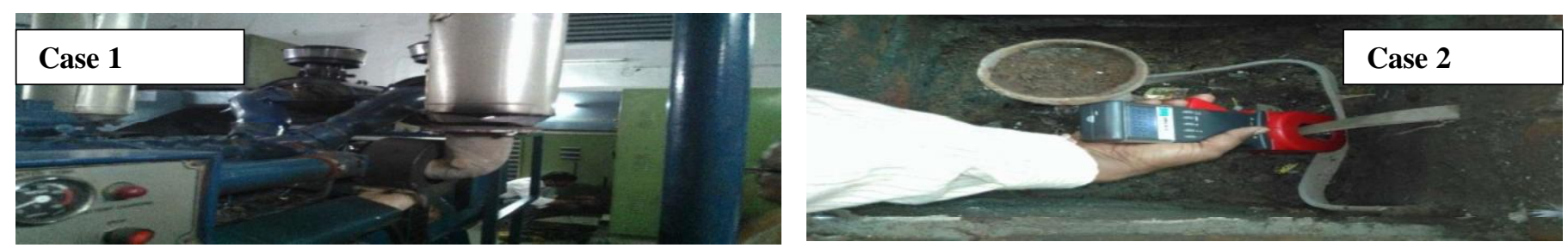

Case 1: Observation: Found Smoke Exhaust damaged. Recommendation: Smoke exhaust should be rectified.

Case 2: Observation: Earth Pit Clearance for regular checking is inadequate. Recommendation: Earth Pit Clearance for regular checking is required.
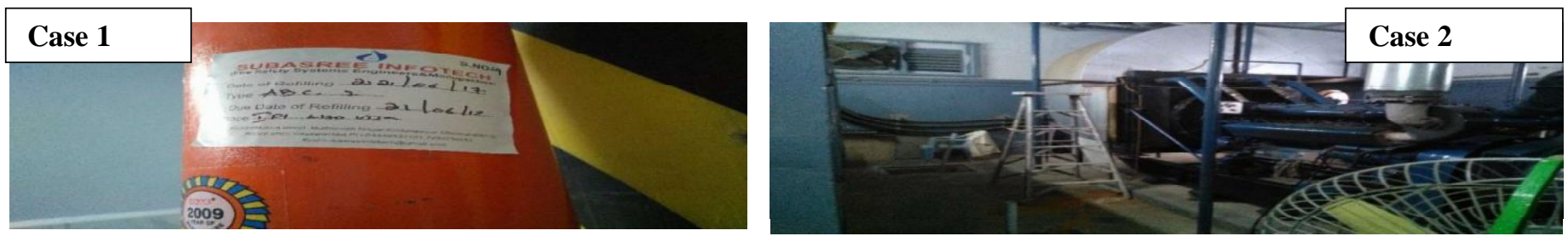

e 1: Observation: Calibration is date expired. Recommendation: Fire Extinguisher should be inspected for regular calibration.

Case 2: Observation: Fire Extinguisher is not available. Recommendation: Fire Extinguisher should be provided.
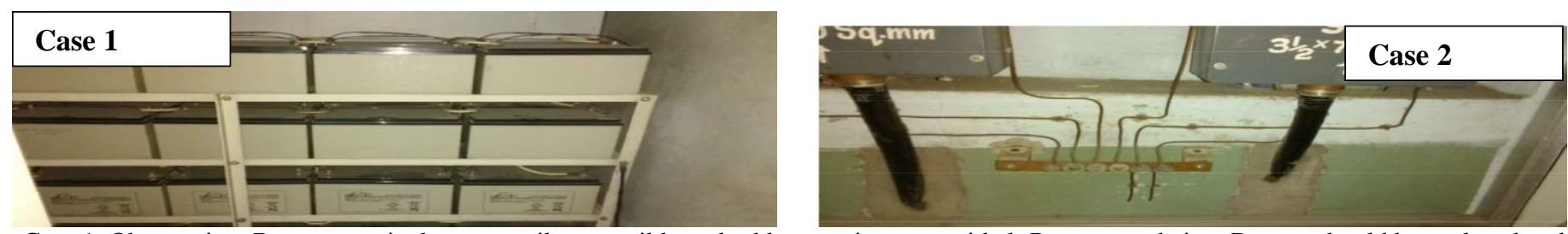

Case 1: Observation: Battery terminals were easily accessible and rubber mat is not provided. Recommendation: Battery should be enclosed and rubber mat should be provided. Case 2: Observation: Cable \& earthing leads are concreted. Recommendation: Cable \& earthing leads should be free from concrete materials.
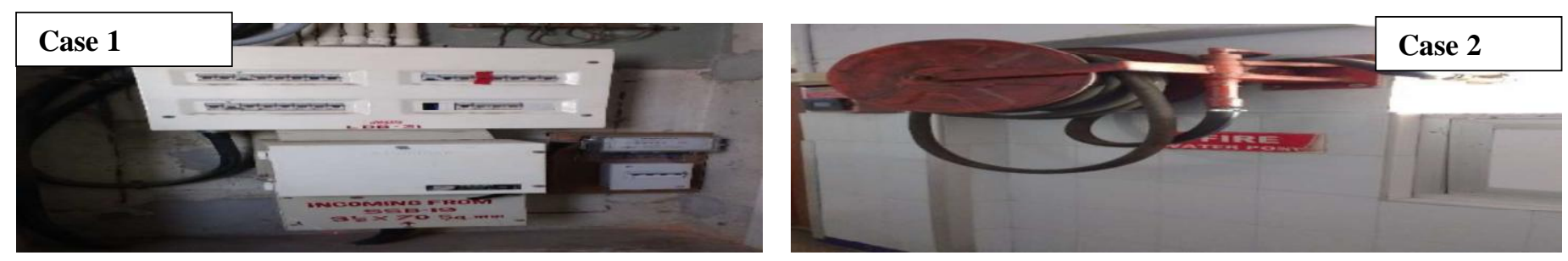

Case 1: Observation: Red Taped overloaded MCB is identified. Recommendation: MCB Should be rated as per the Load design condition. Case 2: Observation: Proper maintenance required for Fire Fighting System. Recommendation: Fire Fighting system should be properly maintained with nozzle holder.

\section{Power Quality Study}

\begin{tabular}{|c|c|c|c|c|c|c|c|c|c|c|c|c|c|c|c|c|c|}
\hline \multirow[b]{2}{*}{ Range } & \multirow{2}{*}{$\begin{array}{c}\text { Transformer } \\
\text { Rating }\end{array}$} & \multicolumn{3}{|c|}{ Voltage } & \multicolumn{3}{|c|}{ Current } & \multicolumn{3}{|c|}{ VTHD } & \multicolumn{3}{|c|}{ ITHD } & \multirow[t]{2}{*}{$\mathrm{Hz}$} & \multirow[t]{2}{*}{ P.F } & \multirow[t]{2}{*}{ KW } & \multirow[t]{2}{*}{ KVA } \\
\hline & & $\mathrm{RPh}$ & Y Ph & B Ph & $\mathrm{RPh}$ & Y Ph & B Ph & $\mathrm{R}$ Ph & Y ph & B Ph & $\mathrm{RPh}$ & Y Ph & B Ph & & & & \\
\hline MAX & \multirow{2}{*}{$500 \mathrm{KVA}$} & 236 & 233 & 234 & 232 & 267 & 253 & & & & & & & 50.13 & 0.99 & 172.08 & 175.08 \\
\hline MIN & & 233 & 231 & 323 & 162 & 211 & 199 & & & & & & & 49.93 & 0.98 & 133.56 & 135.6 \\
\hline AVG & & 234 & 232 & 233 & 195 & 240 & 221 & 1.81 & 1.64 & 1.95 & 6.93 & 4.13 & 8.43 & 50.03 & 0.99 & 151.76 & 154.19 \\
\hline MAX & \multirow{2}{*}{315 KVA } & 237 & 237 & 239 & 264 & 272 & 233 & & & & & & & 50.14 & 0.99 & 177 & 180 \\
\hline MIN & & 232 & 232 & 234 & 177 & 204 & 175 & & & & & & & 49.89 & 0.97 & 130 & 132 \\
\hline AVG & & 236 & 235 & 237 & 217 & 231 & 196 & 2.07 & 1.73 & 1.98 & 8.53 & 4.04 & 7.39 & 50 & 0.99 & 150 & 153 \\
\hline MAX & \multirow{3}{*}{$500 \mathrm{KVA}$} & 236 & 235 & 236 & 528 & 546 & 502 & & & & & & & 50.1 & 0.98 & 349 & 358 \\
\hline MIN & & 231 & 231 & 232 & 273 & 286 & 308 & & & & & & & 49.91 & 0.98 & 213 & 214 \\
\hline AVG & & 234 & 234 & 234 & 355 & 379 & 388 & 1.47 & 1.45 & 1.52 & 4.94 & 4.93 & 4.87 & 50.01 & 0.99 & 262 & 263 \\
\hline MAX & $500 \mathrm{KVA}$ & 233 & 234 & 234 & 579 & 492 & 571 & & & & & & & 50.08 & 0.98 & 369 & 379.38 \\
\hline
\end{tabular}




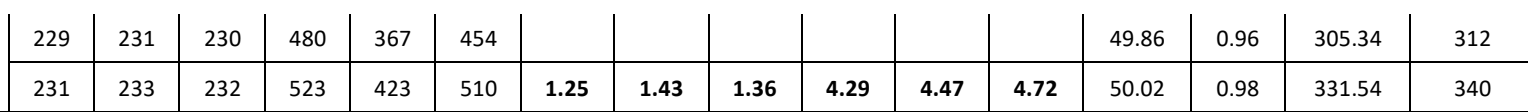

As per the given table the load current across Transformer 2 - $315 \mathrm{KVA}$ shall be changed to transformer 1 - $500 \mathrm{KVA}$ and vice versa in order to reduce the load stress in Transformer $2-315 \mathrm{KVA}$ to reduce overheating heating of transformer. The Transformer overhauling shall be carried out for 2-3 years to achieve good efficiency of Transformer.
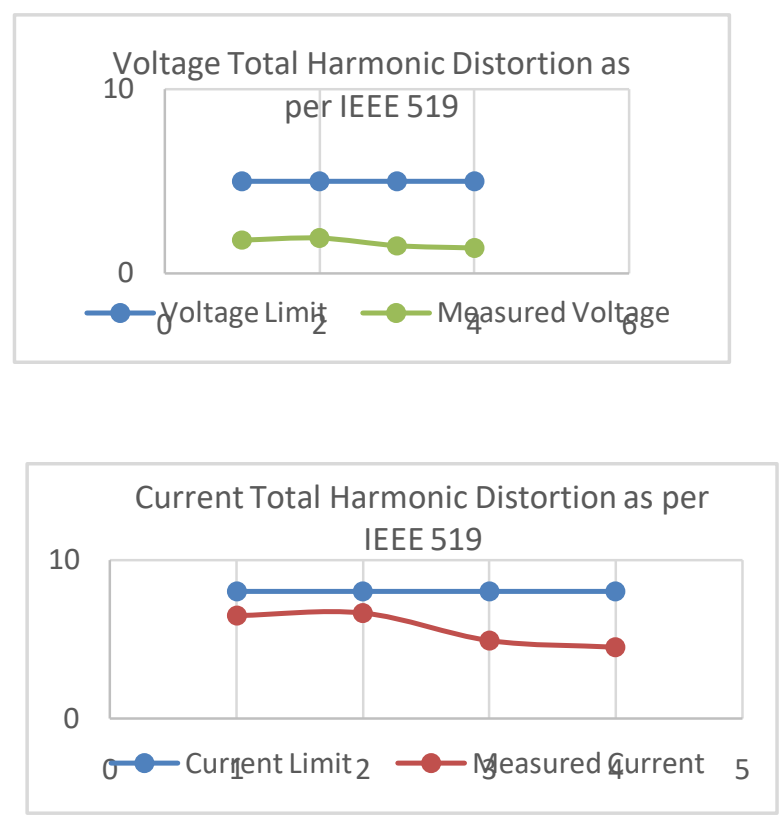

As per IEEE 519 the ITHD - Total Current Harmonics Distorsion should be less than $8 \%$ \& VTHD - Total Voltage Harmonics distorsion should be less than 5\% and the above measured values is within the limits. As per the observation measured the power factor in all the incomers are maintained above 0.95. Voltage fluctuations are within the limit with Unbalanced condition presents in all the incomers. Strictly advised to Split the loads evenly in all incomers to reduce the unbalanced condition and neutral current.

\section{RESULTS \& DISCUSSIONS:}

1. Emergency lighting must be installed in entire rooms \& usage areas.

2. Proper maintenance \& service required for UPS and it should be placed on the proper Rubber mats as per IS 15652 . 3. Batteries should be covered by the proper enclosures.

4. Panel earthing should be provided and cable dressing should be proper in order to avoid any incidents.

5. Cables should be concealed proper \& usage of lower grade Extension box should be avoided and proper rubber mat should be provided as per IS Standard.

6. Due to under rated MCB's \& MCCB's load shedding happened, so segregate the suitable loads in distribution feeders along with appropriate MCB's \& MCCB's.

7. It's advisable to conduct the protection coordination to avoid the nuisance tripping.

8. Ferruling the cable \& name Tag should be provided in the distribution switches.

\section{CONCLUSION:}

The Complete Utility was absorbed in order to achieve Electrical \& Physical safety. Where it is mandatory that all the Electrical Equipment's \& its Parameters should be checked inch by inch for electrical equipment sizing with respect to its load pattern. It was identified that the Load was Unbalancing in all the incoming feeders of Transformer 1, 2, 3, 4 for which we have recommend it should be balanced load wise and load balancing should be achieved. Harmonics Current as well as Voltage is within limit in which the Harmonics Current is $4 \%$, Harmonics Voltage is $1.8 \%$, as per IEEE 519 the harmonics current should be less than $8 \%$ \& harmonics voltage should be less than $5 \%$. This confirms that the utility is not affected by Harmonics Distortion. It was riveted that Lightening Arrestor Fixed Angle Air Termination spike rod is not sufficient in case of heavy parallel lightning strike to the building. The Lightening Arrestor is not covering total surface of the hospital, because there is was a tallest building near to Hospital (ex: Commercial Mall), in case of single lightning strikes, the tallest building will get affected and arrest the strike. In case of two lightning strike immediately one after another then the strike can possibly disturb the Hospital Electrical Equipment's \& its Structure. Earthing Pit Layout of Hospital was checked randomly and we found the pits are in health condition for the betterment earthing efficacy of the earth pits, it should be completely checked for the rusting of the Electrode, Sand filling in the pit and complete monitoring of Earth Pit shall be carried out in regular interval.

\section{REFERENCE}

1. Safety and Health at Work, Volume 7, Issue 4, 2016"An Investigation of Health and Safety Measures in a Hydroelectric Power Plant".

2. International Journal of Advanced Research in Electrical, Electronics and Instrumentation Engineering "A Review on Energy Management and Audit".

3. International Journal of Science and Research (IJSR) ISSN (Online): 2319-7064 Index Copernicus Value (2013) “A Study on Safety Audit Management System in Kuwait"

4. IEEE 403 "IEEE Recommended Practice for Electric Systems in Health Care Facilities".

5. IEEE 142 - 1991 "Grounding of Industrial \& Commercial Power System".

6. IEEE 519 - 2012 "IEEE Recommended Practice and Requirements for Harmonic Control in Electric Power Systems".

7. IEEE 399-1997 "Industrial \& Commercial Power System".

8. IEEE 665-1995 "Generating Station Grounding”.

9. IEC $60479-1$ \& 5 "Effect \& General aspects of Current on Human being \& live stocks".

10. IEEE 80 "Testing of Power System Equipment's. 


\section{AUTHOR PROFILE}

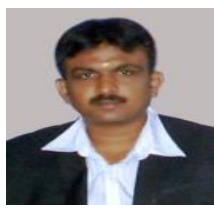

Dr.L. Ramesh received his Doctor of philosophy (Ph.D) July 2015, Thesis titled "Electrical Power Distribution System Optimal Meter Placement and Loss Minimization" from Jadavpur University Kolkata, Electrical Engineering Department. Jadavpur University, Kolkata and he holds Chartered Engineer \& Fellow from Institution of Engineers India.

Er. Vijaykumar Mani completed his Master's in Power System from Saveetha School of Engineering and he is also a certified Energy Auditor from Bureau of Energy Efficiency, GOI and also he is a Chartered Engineer from Institution of Engineers - India. Currently working as Head for MEP \& Power and Construction Department in Applus Velosi - Muscat, Oman. Area of Specialization Electrical Energy \& Safety Audit, ISO Audit in all Verticals.

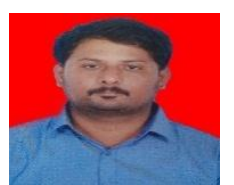

Er.M. Madhusudhana Raju completed his Master's in Power System from Dr.M.G.R Educational \& Research Institute University and also holds Chartered Engineer from Institution of Engineers India. Currently working as Electrical Engineer in Applus Velosi - Muscat, Oman. Area of Specialization are Testing of Electrical Equipments in Substations, Electrical Safety \& Energy Audit, Power Quality Analysis with Mitigation Techniques. 